\title{
Associations among High Risk for Sleep-disordered Breathing, Related Risk Factors, and Attention Deficit/Hyperactivity Symptoms in Elementary School Children
}

\author{
Kyoung Min Kim${ }^{1}$, Jee Hyun Kim², Dohyun Kim ${ }^{3}$, Myung Ho Lim$^{4}$, Hyunjoo Joo ${ }^{5}$, Seung-Jin Yoo ${ }^{6}$, \\ Eunjung Kim ${ }^{6}$, Mina $\mathrm{Ha}^{5}$, Ki Chung Paik ${ }^{1,6}$, Ho-Jang Kwon ${ }^{5,6}$ \\ ${ }^{1}$ Department of Psychiatry, Dankook University College of Medicine, ${ }^{2}$ Department of Neurology, Dankook University Hospital, Dankook \\ University College of Medicine, ${ }^{3}$ Department of Psychiatry, Dankook University Hospital, ${ }^{4}$ Department of Psychology, College of Public Human \\ Resources, Dankook University, ${ }^{5}$ Department of Preventive Medicine, Dankook University College of Medicine, ${ }^{6}$ Environmental Health Center, \\ Dankook University Medical Center, Cheonan, Korea
}

\begin{abstract}
Objective: Habitual snoring is a common problem in children. We evaluated the association between a high risk for sleep-disordered breathing and attention deficit/hyperactivity symptoms.

Methods: Parents of 13,560 children aged 6 to 12 years responded to questionnaires including items on habitual snoring and the Korean attention deficit/hyperactivity disorder rating scale. The snoring score comprised the number of "yes" responses to habitual-snoring items, and a high risk for sleep-disordered breathing was defined as a snoring score $\geq 2$. Results: The odds ratio (OR) of a high risk for sleep-disordered breathing was significantly higher in boys (OR = 1.47; $p<0.001)$, overweight children $(\mathrm{OR}=2.20 ; p<0.001)$, and children with current secondhand-smoking exposure $(\mathrm{OR}=1.38 ; p<0.001)$. The Korean attention deficit/hyperactivity disorder rating scale score increased significantly with the snoring score ( 0 vs. $1, \mathrm{~B}=1.56, p<0.001 ; 0$ vs. $2, \mathrm{~B}=2.44, p<0.001 ; 0$ vs. $3, \mathrm{~B}=2.48, p<0.001$; 0 vs. $4, \mathrm{~B}=3.95 ; p<0.001)$.

Conclusion: Our study confirms several risk factors of sleep-disordered breathing, namely male sex, overweight, and exposure to tobacco smoking, and found a positive association between habitual snoring and attention deficit/hyperactivity symptoms.
\end{abstract}

KEY WORDS: Sleep-disordered breathing; Attention deficit/hyperactivity disorder; Risk factors; Elementary school children.

\section{INTRODUCTION}

Snoring is a sign of increased resistance in the upper airway during sleep and a cardinal symptom of sleep-disordered breathing (SDB) [1]. SDB is a common sleep problem [2], with the spectral continuum ranging from

Received: August 28, 2019 / Revised: December 18, 2019

Accepted: January 3, 2020

Address for correspondence: Kyoung Min Kim

Department of Psychiatry, Dankook University College of

Medicine, 119 Dandae-ro, Dongnam-gu, Cheonan 31116, Korea

E-mail: profuture@naver.com

ORCID: https://orcid.org/0000-0003-0577-0701

Ho-Jang Kwon

Department of Preventive Medicine, Dankook University College of Medicine, 119 Dandae-ro, Dongnam-gu, Cheonan 31116,

Korea

E-mail: hojangkwon@gmail.com

ORCID: https://orcid.org/0000-0003-3029-5674 the mild form of primary snoring or habitual snoring to the severest form of obstructive sleep apnea syndrome (OSAS) [2].

The prevalence of SDB in children has been reported to vary widely according to the defining criterion, such as snoring frequency, used in different studies. Lumeng and Chervin [3] reported, in a meta-analytic study, a prevalence of parent-reported "always" snoring of $1.5 \%$ to $6.0 \%$ and of apneic events during sleep of $0.2 \%$ to $4 \%$, in a population of children and adolescents under 18 years of age. They also reported an overall prevalence of parent-reported snoring by any definition of $7.45 \%$. Earlier studies in South Korean child and adolescent populations reported a prevalence of habitual snoring of $11.2 \%$ in high school students [4] and $16.5 \%$ in elementary school children [5].

@) This is an Open-Access article distributed under the terms of the Creative Commons Attribution Non-Commercial License (http://creativecommons.org/licenses/by-nc/4.0) which permits unrestricted non-commercial use, distribution, and reproduction in any medium, provided the original work is properly cited. 
While adenotonsillar hypertrophy is the most common cause of SDB due to the obstruction of the upper airway, with a peak at age 3 to 5 years [2], multiple risk factors such as obesity [6], asthma [7], race [8], and exposure to secondhand smoking (SHS) [9] have been reported to contribute to the development of SDB.

Obesity is one of the commonly reported risk factors for SDB, with the reported prevalence of OSAS in obese children and adolescents as high as $13 \%$ to $69 \%$ [10]. Exposure to SHS has also been reported as a risk factor for SDB, due to the possibility of chronic upper airway inflammation. Sun and colleagues [9] reported an odds ratio (OR) of habitual snoring in children exposed to SHS of 1.46, 1.45, and 1.87 for household, paternal, and maternal smoking exposure, respectively, and an OR of 1.95 for prenatal exposure to SHS. Breastfeeding during infancy has been reported as another risk factor of SDB $[11,12]$. A birth cohort study reported that breastfeeding for longer than 1 month was associated with a reduced risk $(O R=0.48)$ of habitual snoring at age 8 [12].

Multiple studies have investigated the behavioral and psychological characteristics of children with SDB and reported consistently that SDB is associated with unfavorable characteristics such as depression and anxiety as well as with hyperactivity, impulsivity, and inattention, which are core symptoms of attention deficit/hyperactivity disorder (ADHD) [13]. Sedky and colleagues [14] reported a moderate relationship between SDB and ADHD (Hedges' $g=0.57$ ), and Amiri and colleagues [15] reported that adenotonsillectomy in children with SDB resulted in a significant decrease in ADHD symptom severity. Other studies reported that the frequency of snoring, rather than the apnea-hypopnea index, predicted cognitive and behavioral problems in young children [16].

While a number of previous studies have investigated the risk factors of SDB and its association with ADHD symptoms, to our knowledge, no earlier study has been conducted with a large sample of elementary school children, especially in South Korea. We therefore investigated the risk factors of SDB and its association with behavioral outcomes in terms of ADHD symptoms in a large-scale, cross-sectional survey.

\section{METHODS}

\section{Participants}

Parents of 13,560 elementary school children in Cheonan, which is a medium-sized city with a mixture of industrialized urban and rural areas in South Korea, were invited to respond to the survey including health- and sleep-related questionnaires as part of a screening for neurodevelopmental disorders over a period from 2009 to 2010. All parents were provided with information regarding the purpose of the study, and they all provided written informed consent. The study protocol was approved by the institutional review board of Dankook University Hospital in Cheonan (DKUH-0801-006).

\section{Questionnaire}

The questionnaire included demographic characteristics such as sex, age, height, weight, parental educational level, breastfeeding during infancy, and prenatal and current exposure to SHS. To assess the SDB risk and symptoms, the Pediatric Sleep Questionnaire (PSQ) was utilized [17]. The PSQ is a questionnaire that assesses the multi-dimensional sleep problems of children, with the responses "yes" =1, "no" = 0 , and "don't know" = blank. The Sleep-Related Breathing Disorder (SRBD) scale is derived from the PSQ, which consists of 22 items for total scores and three subscales of snoring (four items), sleepiness (four items), and behavior (six items). The SRBD scale has been used in multiple studies and reported to be a valid and reliable screening instrument with the ability to identify a high risk for OSA when polysomnography cannot be conducted $[17,18]$. As the optimal cut-off value of the SRBD scale, a mean value of 0.33 for the identification of pediatric OSA has been suggested. The snoring subscale of the SRBD scale, which consists of four items (A2: "snore more than half the time?", A3: "always snore?", A4: "snore loudly?", and A5: "have "heavy" or loud breathing?"), showed a stronger association with mean sleep latency and SRBD diagnosis (area under receiver operator curve $[R O C]=0.85$ ) than the other two subscales, sleepiness (area under ROC $=0.80$ ) and behavior (area under $\mathrm{ROC}=0.84)[17,18]$. Although the predictive value of the SRBD overall score is better than that of the snoring subscale, we adopted only the four items of the snoring subscale for our brief questionnaire, to improve response rates considering the large number of participants. The 
snoring score was calculated as the number of "yes" responses to the four items. As the total score of snoring-related items ranged from 0 to 4 , we defined the high-risk group for SDB as the group with a total score of snoring-related items equal to or higher than 2 points, which corresponds to the cut-off value of 0.33 of the SRBD scale.

To assess ADHD symptoms, the Korean version of the $\mathrm{ADHD}$ rating scale (K-ARS) was used. The K-ARS is a checklist for assessing ADHD symptom severity, developed by Dupaul et al. [19] and validated in multiple countries [20]. The K-ARS consists of 18 items rated on a 4-point scale from 0 to 3 points, with the response options "never or rarely", “sometimes”, “often”, and "very often”. The Korean version of the K-ARS was translated and validated by So et al. [21] and has been used in a number of studies in South Korean children [22,23]. The Cronbach's alpha values of the K-ARS total score and the hyperactivity-impulsivity and inattention subscale scores in the present study were $0.904,0.812$, and 0.859 , respectively. The high-risk ADHD group included participants with a total ADHD score equal to or higher than 19.

\section{Statistical Analysis}

Statistical analyses were conducted using the software package SPSS 25.0 for Windows (IBM Co., Armonk, NY, USA). Demographic variables and environmental factors such as sex, age, body mass index (BMI), and exposure to SHS were compared between the "yes" and "no" response groups for each snoring-related item using chi-square tests and independent $t$ tests for categorical and continuous variables, respectively. The overweight group included children with a BMI above the 85th percentile in the 2007 Korean National Growth Charts [24]. Logistic regression was performed to investigate the associations between a high risk for SDB and all related factors, including age, sex, overweight, current exposure to secondhand smoking, and paternal smoking during pregnancy with the high risk for SDB (snoring score $\geq 2$ ) as the binary dependent variable. Generalized linear regression was used to analyze the associations between total K-ARS scores and related factors, including the snoring scores, age, sex, parental educational level, overweight, breast feeding, current exposure to secondhand smoking, and paternal smoking during pregnancy. Due to the high number of missing data on paternal smoking during pregnancy, this factor was included in a separate model (model 2) in the
Table 1. Demographic characteristics of the participants

\begin{tabular}{lc}
\hline \multicolumn{1}{c}{ Variable } & Value \\
\hline Total & 13,042 \\
Male & $6,512(49.9)$ \\
Age & $9.07 \pm 1.78$ \\
Paternal education (yr) & \\
$<12$ & $250(1.9)$ \\
12 & $4,745(36.4)$ \\
$>12$ & $7,480(57.4)$ \\
Unknown & $567(4.3)$ \\
Maternal education (yr) & \\
$<12$ & $235(1.8)$ \\
12 & $6,718(51.5)$ \\
$>12$ & $5,469(41.9)$ \\
Unknown & $620(4.8)$ \\
Overweight & \\
No & $11,570(88.7)$ \\
Yes & $1,472(11.3)$ \\
Breast feeding & \\
No & $5,685(43.6)$ \\
Yes & $7,022(53.8)$ \\
Unknown & $335(2.6)$ \\
Paternal smoking during pregnancy & \\
No & $4,454(34.9)$ \\
Yes & $7,105(54.5)$ \\
Unknown & $1,383(10.6)$ \\
Maternal smoking during pregnancy & \\
No & $9,647(74.0)$ \\
Yes & $38(0.3)$ \\
Unknown & $3,357(25.7)$ \\
Current exposure to secondhand smoking & \\
No & $8,109(62.2)$ \\
Yes & $4,546(34.9)$ \\
Unknown & $387(3.0)$ \\
\hline Vo & \\
\hline & \\
\hline & \\
\hline &
\end{tabular}

Values are presented as number $(\%)$ or mean \pm standard deviation.

logistic regression and generalized linear regression analysis, to avoid a bias. In total, 115, 138, and 265 questionnaires had missing data for sex, age, and snoring items, respectively, and were thus excluded. Finally, 13,042 children were included in the analysis.

\section{RESULTS}

\section{Demographic Characteristics and Proportion of Children at High Risk for SDB}

Among the participants, there were 6,512 (49.9\%) boys, and the mean age of the participants was 9.07 years, ranging from 6 to 12 years (Table 1). The "yes" response rate for each item and the distribution of habitual snoring scores is shown in Table 2. The rate of "yes" responses for each item was $5.1 \%$ to $5.8 \%$, and the proportion of chil- 
dren whose parent responded "yes" to at least one item was $12.6 \%$. The ratio of high-risk children, that is, those with a snoring score $\geq 2$, was $5.7 \%$.

\section{Risk Factors Associated with SDB}

SDB-related risk factors are listed in Table 3. Ratios of male/female sex, BMI, exposure to prenatal paternal smoking, and current exposure to SHS differed significantly between the high-risk and the non-high-risk groups. In the logistic regression analysis, male sex, overweight, and current exposure to secondhand smoking were significantly associated with a high risk for SDB (Table 4).

Table 2. Responses to the habitual snoring questionnaire

\begin{tabular}{lcc}
\hline \multicolumn{1}{c}{ Items for habitual snoring } & Yes & No \\
\hline Snore more than half the time? & $750(5.8)$ & $11,292(94.2)$ \\
Always snore? & $757(5.8)$ & $12,285(94.2)$ \\
Snore loudly? & $665(5.1)$ & $12,377(94.9)$ \\
Have "heavy" or loud breathing? $^{\text {Snoring score }}$ a & $769(5.9)$ & $12,273(94.1)$ \\
0 & & \\
1 & $11,397(87.4)$ & \\
2 & $896(6.9)$ & \\
3 & $352(2.7)$ & \\
4 & $247(1.9)$ & \\
$\geq 2$ & $150(1.2)$ & \\
\hline
\end{tabular}

Values are presented as number (\%).

aThe snoring score represents the sum of “yes" responses to each item of the habitual snoring questionnaire. Percentages in brackets indicate the proportion of respondents with this score.

\section{ADHD Symptoms and SDB Scores}

Table 5 shows the scores for the K-ARS and its subscales, according to the responses to snoring items and

Table 3. Risk factors for high risk for sleep-disordered breathing (snoring score $\geq 2$ )

\begin{tabular}{lccrr}
\hline \multicolumn{1}{c}{ Variable } & $\begin{array}{c}\text { High risk } \\
\text { SDB }\end{array}$ & $\begin{array}{c}\text { Low risk } \\
\text { SDB }\end{array}$ & t or $\chi^{2}$ & $p$ value \\
\hline Age & $9.08 \pm 1.80$ & $9.07 \pm 1.77$ & 0.200 & 0.842 \\
Sex & & & 24.693 & $<0.001$ \\
$\quad$ Male & $440(6.8)$ & $6,072(93.2)$ & & \\
$\quad$ Female & $309(4.7)$ & $6,221(95.3)$ & & \\
Body mass index & $18.78 \pm 3.55$ & $17.46 \pm 2.81$ & 9.057 & $<0.001$ \\
Overweight & & & 98.547 & $<0.001$ \\
No & $581(5.0)$ & $10,989(95.0)$ & & \\
Yes & $168(11.4)$ & $1,304(88.6)$ & & \\
Birth weight & $3.26 \pm 0.44$ & $3.26 \pm 0.46$ & 0.008 & 0.929 \\
Breast feeding & \multicolumn{5}{c}{0.159} & 0.923 \\
$\quad$ No & $328(5.8)$ & $5,357(94.2)$ & & \\
$\quad$ Yes & $396(5.6)$ & $6,626(94.4)$ & & \\
Paternal smoking during pregnancy & 7.089 & 0.008 \\
No & $232(5.1)$ & $4,322(94.9)$ & & \\
Yes & $446(6.3)$ & $6,659(93.7)$ & & \\
Maternal smoking during pregnancy & 1.787 & 0.181 \\
No & $535(5.5)$ & $9,112(94.5)$ & & \\
Yes & $4(10.5)$ & $34(89.5)$ & & \\
Current exposure to secondhand smoking & 29.879 & $<0.001$ \\
No & $396(4.9)$ & $7,713(95.1)$ & & \\
Yes & $329(7.2)$ & $4,217(92.8)$ & & \\
\hline
\end{tabular}

Values are presented as mean \pm standard deviation or number $(\%)$ SDB, sleep-disordered breathing.

Age was compared with independent $t$ tests, and chi-squared tests were used for other variables.

Table 4. Odds ratio $(\mathrm{OR})$ and $95 \%$ confidence interval $(\mathrm{Cl})$ for high risk for sleep-disordered breathing (snoring score $\geq 2$ )

\begin{tabular}{|c|c|c|c|c|c|c|}
\hline \multirow{2}{*}{ Variable } & \multicolumn{3}{|c|}{ Model 1} & \multicolumn{3}{|c|}{ Model 2} \\
\hline & OR & $95 \% \mathrm{Cl}$ & $p$ value & OR & $95 \% \mathrm{Cl}$ & $p$ value \\
\hline Age & 1.00 & $0.96-1.04$ & 0.983 & 1.01 & $0.96-1.05$ & 0.823 \\
\hline \multicolumn{7}{|l|}{ Sex } \\
\hline Female & Referent & & & Referent & & \\
\hline Male & 1.41 & $1.21-1.64$ & $<0.001$ & 1.47 & $1.25-1.72$ & $<0.001$ \\
\hline \multicolumn{7}{|l|}{ Overweight } \\
\hline No & Referent & & & Referent & & \\
\hline Yes & 2.30 & $1.91-2.76$ & $<0.001$ & 2.20 & $1.81-2.67$ & $<0.001$ \\
\hline \multicolumn{7}{|c|}{ Current exposure to secondhand smoking } \\
\hline No & Referent & & & Referent & & \\
\hline Yes & 1.48 & $1.27-1.73$ & $<0.001$ & 1.38 & $1.17-1.63$ & $<0.001$ \\
\hline \multicolumn{7}{|c|}{ Paternal smoking during pregnancy } \\
\hline No & & & & Referent & & \\
\hline Yes & & & & 1.11 & $0.93-1.32$ & 0.241 \\
\hline
\end{tabular}

Logistic regression analysis was utilized to investigate the associations between a high risk for sleep-disordered breathing (SDB) and related factors by two models with the high risk for SDB (snoring score $\geq 2$ ) as the binary dependent variable. Model 1 includes age, sex, overweight and current exposure to secondhand smoking as covariates $(n=12,655)$. Model 2 includes paternal smoking during pregnancy as covariates in addition to model $1(n=11,451)$ 
Table 5. ADHD symptom scores according to snoring scores

\begin{tabular}{|c|c|c|c|c|}
\hline Scores on ADHD symptom & Yes & No & $\mathrm{t}$ & $p$ value \\
\hline \multicolumn{5}{|l|}{ K-ARS total score } \\
\hline Snore more than half the time? & $10.85 \pm 8.41$ & $7.71 \pm 6.75$ & 9.997 & $<0.001$ \\
\hline Always snore? & $10.63 \pm 8.17$ & $7.72 \pm 6.78$ & 9.547 & $<0.001$ \\
\hline Snore loudly? & $10.53 \pm 6.87$ & $7.75 \pm 6.81$ & 8.916 & $<0.001$ \\
\hline Have "heavy" or loud breathing? & $10.69 \pm 7.68$ & $7.72 \pm 6.81$ & 10.434 & $<0.001$ \\
\hline \multicolumn{5}{|l|}{ Snoring scoring $\geq 2$} \\
\hline K-ARS total & $11.04 \pm 8.16$ & $7.70 \pm 6.77$ & 10.926 & $<0.001$ \\
\hline K-ARS hyperactivity & $4.40 \pm 4.08$ & $2.95 \pm 3.25$ & 9.539 & $<0.001$ \\
\hline $\mathrm{K}-\mathrm{ARS}$ inattention & $6.64 \pm 4.67$ & $4.75 \pm 3.99$ & 10.776 & $<0.001$ \\
\hline K-ARS high risk group & & & 70.631 & $<0.001$ \\
\hline Yes & $118(11.6)$ & $899(88.4)$ & & \\
\hline No & $623(5.2)$ & $11,302(94.8)$ & & \\
\hline
\end{tabular}

Values are presented as mean \pm standard deviation or number (\%).

The Korean version of the ADHD rating scale (K-ARS) scores and subscales are presented according to the responses to each item on the habitual snoring questionnaire. The snoring score represents the sum of "yes" responses to each item of the habitual snoring questionnaire.

$\mathrm{ADHD}$, attention deficit/hyperactivity disorder.

Independent $t$ tests were utilized for the comparison between scores.

snoring scores. The K-ARS scores of the high-risk SDB group were significantly higher than those of the SDB non-high-risk group. Higher snoring scores showed a significantly positive association with higher total scores on the K-ARS (Table 6). Age, sex, prenatal parental smoking, current exposure to secondhand smoking, and paternal education level were also significantly associated with the total K-ARS scores.

\section{DISCUSSION}

The present study investigated the risk factors of SDB and its association with ADHD symptoms in a large sample of elementary school children in South Korea. The prevalence of SDB has been reported to vary widely, depending on the defining criterion for the frequency and aspects of SDB [3]. In our study, $12.6 \%$ of parents responded "yes" to at least one item, and the prevalence of a high risk for SDB was $5.7 \%$. These results are comparable to those of previous studies. Various international studies with children between 5 and 13 years of age have reported a prevalence of habitual snoring of $2.4 \%$ to 10.9\% [25-28]. Studies conducted in Hong Kong and Thailand reported a prevalence of $10.9 \%$ and $8.5 \%$, respectively $[29,30]$.

In our study, the proportion of children at high risk for SDB did not significantly differ between different age groups. The prevalence of SDB has been reported to in- crease between 2 and 5 years of age [31] due to the narrowing of the pharyngeal airway, as a result of the more rapid growth of soft airway tissues (compared to the skeleton) between 3 and 5 years of age [2]. Papaioannou and colleagues [32] also reported that growing adenotonsillar tissue narrows the upper airway during early life, with a peak at the age of 6 years, and adenotonsillar hypertrophy has been reported as a major determinant of OSA in children but not in adolescents [33]. The non-significant association between age and SDB prevalence in our study might be explained by the older age range of our population, considering the period of soft upper airway tissue overgrowth.

We found significant sex differences in the risk for SDB in the present study, with a higher OR ratio (1.434) in boys. This is an interesting finding considering that our subjects were elementary school children aged 6 to 13 years of age. Lumeng and Chervin [3] reported a higher prevalence of childhood SDB in boys, approximately $50 \%$ to $100 \%$ higher than in girls, in a meta-analytic study. However, studies with participants at the pre-pubertal stage, that is, under 13 years of age, more commonly report no sex differences in SDB prevalence. Lumeng and Chervin [3] therefore suggested a potential mediating effect of puberty-related hormonal changes on higher SDB prevalence in boys, because studies that did report sex differences often included older children above 13 years of age. 
Table 6. Generalized linear regression model for total K-ARS scores

\begin{tabular}{|c|c|c|c|c|c|c|}
\hline \multirow{2}{*}{ Variable } & \multicolumn{3}{|c|}{ Model 1} & \multicolumn{3}{|c|}{ Model 2} \\
\hline & B (s.e.) & $95 \% \mathrm{Cl}$ & $p$ value & B (s.e.) & $95 \% \mathrm{Cl}$ & $p$ value \\
\hline \multicolumn{7}{|c|}{ Snoring score } \\
\hline 0 & Referent & & & Referent & & \\
\hline 1 & $1.62(0.24)$ & 1.15 to 2.09 & $<0.001$ & $1.56(0.25)$ & 1.08 to 2.05 & $<0.001$ \\
\hline 2 & $2.39(0.38)$ & 1.65 to 3.13 & $<0.001$ & $2.44(0.39)$ & 1.67 to 3.21 & $<0.001$ \\
\hline 3 & $2.47(0.45)$ & 1.58 to 3.35 & $<0.001$ & $2.48(0.47)$ & 1.56 to 3.41 & $<0.001$ \\
\hline 4 & $3.80(0.57)$ & 2.68 to 4.91 & $<0.001$ & $3.95(0.59)$ & 2.8 to 5.11 & $<0.001$ \\
\hline Age & $-0.12(0.03)$ & -0.18 to -0.05 & 0.001 & $-0.11(0.04)$ & -0.18 to -0.04 & 0.002 \\
\hline \multicolumn{7}{|l|}{ Sex } \\
\hline Male & Referent & & & Referent & & \\
\hline Female & $-2.76(0.12)$ & -3 to -2.53 & $<0.001$ & $-2.78(0.13)$ & -3.02 to -2.53 & $<0.001$ \\
\hline \multicolumn{7}{|c|}{ Paternal education (yr) } \\
\hline$<12$ & Referent & & & Referent & & \\
\hline 12 & $-2.82(0.52)$ & -3.83 to -1.8 & $<0.001$ & $-2.67(0.54)$ & -3.72 to -1.62 & $<0.001$ \\
\hline$>12$ & $-3.5(0.53)$ & -4.53 to -2.47 & $<0.001$ & $-3.36(0.55)$ & -4.43 to -2.29 & $<0.001$ \\
\hline \multicolumn{7}{|c|}{ Maternal education (yr) } \\
\hline$<12$ & Referent & & & Referent & & \\
\hline 12 & $-1.63(0.52)$ & -2.64 to -0.61 & 0.002 & $-1.43(0.54)$ & -2.49 to -0.38 & 0.008 \\
\hline$>12$ & $-2.06(0.53)$ & -3.11 to -1.02 & $<0.001$ & $-1.88(0.55)$ & -2.96 to -0.79 & 0.001 \\
\hline \multicolumn{7}{|l|}{ Overweight } \\
\hline No & Referent & & & Referent & & \\
\hline Yes & $-0.10(0.19)$ & -0.47 to 0.27 & 0.604 & $-0.17(0.2)$ & -0.56 to 0.22 & 0.385 \\
\hline \multicolumn{7}{|c|}{ Current exposure to secondhand smoking } \\
\hline No & Referent & & & Referent & & \\
\hline Yes & $1.51(0.13)$ & 1.26 to 1.77 & $<0.001$ & $1.39(0.14)$ & 1.12 to 1.66 & $<0.001$ \\
\hline \multicolumn{7}{|c|}{ Breast feeding } \\
\hline No & Referent & & & Referent & & \\
\hline Yes & $-0.18(0.12)$ & -0.42 to 0.05 & 0.128 & $-0.17(0.13)$ & -0.42 to 0.07 & 0.169 \\
\hline \multicolumn{7}{|c|}{ Paternal smoking during pregnancy } \\
\hline No & & & & Referent & & \\
\hline Yes & & & & $0.41(0.13)$ & 0.15 to 0.67 & 0.002 \\
\hline
\end{tabular}

Generalized linear regression was utilized to analyze the association between the Korean version of the ADHD rating scale (K-ARS) total score and the related variables by two models. Model 1 includes snoring score, age, sex, parental educational level, overweight, current exposure to secondhand smoking, and breast feeding as covariates $(n=11,733)$. Model 2 includes paternal smoking during pregnancy as covariates in addition to model 1 ( $\mathrm{n}=10,739)$.

ADHD, attention deficit/hyperactivity disorder; s.e., standard error.

Various studies have reported that obesity is one of the major risk factors for SDB, with a prevalence of SDB in obese children of $13 \%$ to $59 \%$ [34]. For instance, a German study demonstrated that obese children had a more than four times higher risk of snoring compared to children with a BMI below the 75th percentile [35]. Our study also showed that obesity is positively associated with a high risk for SDB. Obesity might contribute to adenoid and tonsil hypertrophy, which has been suggested as a major risk factor for SDB. Indeed, obese children with OSAS were seven and four times more likely to have enlarged tonsils and adenoids, respectively [36]; obesity-related overgrowth in fat pads, the soft palate, and the tongue might promote upper airway obstruction and SDB [6].

Our study showed an association between exposure to SHS and an increased OR for a high risk for SDB. Passive smoking might induce upper airway inflammation and the narrowing of the pharynx, thus resulting in habitual snoring [9]. In spite of some contradictory results on whether there is a significant association between exposure to SHS and an increased OR for SDB [37,38], a meta-analytic study reported a significant positive association between exposure to SHS and habitual snoring, with an increased OR for habitual snoring of 1.46 for household smoking, 1.45 for paternal smoking, 1.87 for mater- 
nal smoking, and 1.95 for prenatal tobacco smoking exposure [9]. The authors also reported a linear dose-response association between household smoke exposure and habitual snoring. Our results are thus in line with those of previous studies.

Finally, the results on the association between habitual snoring and K-ARS scores represent a major confirmation of the previous evidence on the association between SDB and ADHD. The K-ARS scores in the high-risk SDB group were significantly higher than those in the non-high-risk group. Moreover, higher snoring scores were significantly associated with higher K-ARS scores, which is consistent with the findings of previous studies. For instance, Youssef and colleagues [39] reported in a meta-analytic study a high incidence of $20 \%$ to $30 \%$ of OSA in patients with full syndromal ADHD as well as attentional deficits in $95 \%$ of patients with OSA. Most previous studies on the association between OSA and behavioral functions in children have reported that OSA is associated with internalizing and externalizing problems such as hyperactivity, attention deficits, aggressiveness, anxiety, and social and thought problems in children [40-44].

ADHD is a multi-factorial disease that is affected by various environmental factors, with an important contribution of genetic factors [45]. Our study indicates that smoking exposure, parental education level, age, and sex are also associated with K-ARS scores. Thus, we cannot conclude that SDB is the unique or main cause of $\mathrm{ADHD}$ symptom. Nevertheless, a number of previous studies have consistently reported that SDB affects the behavioral and cognitive functions of children negatively.

While SDB might not be the major cause of ADHD, some children with ADHD symptoms may be affected by SDB. Notably, although we cannot determine whether those who were reported to have habitual snoring had primary snoring or OSA, the frequency of snoring, rather than the apnea-hypopnea index, has been reported to predict cognitive and behavioral problems in young children [16]. Thus, when a child visits a hospital due to ADHD symptoms, screening for habitual snoring or breathing difficulties during sleep might help the clinician when determining an evaluation and treatment plan. Recommended guidelines for ADHD do indeed include an assessment of sleep apnea for the evaluation of children with ADHD [46].

Our study has some limitations that should be noted.
First, the "high risk for SDB" and the "ADHD symptoms" should not be equated with SDB and ADHD, because our study represents a community-based survey and the participating children did not have a medical diagnosis of SDB and/or ADHD. In addition, all SDB symptoms and related factors were assessed by questionnaires answered by the children's parents, and no objective measurement method was included in the study. This could lead to incorrect reports due to, for example, recall biases. The history of prenatal exposure to SHS could, for example, be incorrectly reported by the parents. Parent-reported weight and height in our study could also have been subject to bias, considering previous studies reporting misrepresentation of children's weight by their parents [47]. While the parents' ratings of their children's ADHD symptoms might as well have been somewhat incorrect, it has been reported that parent ratings of ADHD symptoms overlap more consistently with the diagnosis by a clinician than do other psychological problems [48]. Notably, even though the SRBD scale is a valid tool to identify children at a high risk for OSA in epidemiologic studies $[17,18]$, objective measurements such as polysomnography are needed for the exact evaluation and diagnosis of SDB in future studies. Finally, missing data on demographics and related factors may have potentially distorted our findings.

Despite some limitations, our study confirmed the risk factors of habitual snoring in a large sample of elementary school children. Moreover, we found a positive association between habitual snoring and ADHD symptoms. These findings provide important clinical information for the evaluation of children with SDB.

\section{Acknowledgments}

This study was financially supported by the Ministry of Environment, Republic of Korea. The funding source had no involvement in any of study design and collection, analysis and interpretation of data, and writing of the article.

\section{- Conflicts of Interest}

No potential conflict of interest relevant to this article was reported.

\section{Author Contributions}

Conceptualization: Kyoung Min Kim, Jee Hyun Kim, Ki Chung Paik, Mina Ha, Ho-Jang Kwon, Myung Ho Lim. 
Data acquisition: Seung-Jin Yoo, Eunjung Kim, Mina Ha, Ho-Jang Kwon, Ki Chung Paik, Myung Ho Lim. Formal analysis: Kyoung Min Kim, Jee Hyun Kim, Seung-Jin Yoo, Hyunjoo Joo. Draft writing: Kyoung Min Kim, Dohyun Kim. Review and editting: Kyoung Min Kim, Jee Hyun Kim, Dohyun Kim, Ho-Jang Kwon.

ORCID
Kyoung Min Kim Jee Hyun Kim

Dohyun Kim Myung Ho Lim Hyunjoo Joo

Seung-Jin Yoo Eunjung Kim

Mina $\mathrm{Ha}$

Ki Chung Paik

Ho-Jang Kwon https://orcid.org/0000-0003-0577-0701 https://orcid.org/0000-0002-8142-4635 https://orcid.org/0000-0002-6069-2032 https://orcid.org/0000-0001-5370-4376 https://orcid.org/0000-0002-2791-158X https://orcid.org/0000-0002-0643-5609 https://orcid.org/0000-0002-3285-6968 https://orcid.org/0000-0003-1011-9446 https://orcid.org/0000-0003-0465-8371 https://orcid.org/0000-0003-3029-5674

\section{REFERENCES}

1. Kuehni CE, Strippoli MP, Chauliac ES, Silverman M. Snoring in preschool children: prevalence, severity and risk factors. Eur Respir J 2008;31:326-333.

2. Katz ES, D'Ambrosio CM. Pathophysiology of pediatric obstructive sleep apnea. Proc Am Thorac Soc 2008;5:253-262.

3. Lumeng JC, Chervin RD. Epidemiology of pediatric obstructive sleep apnea. Proc Am Thorac Soc 2008;5:242-252.

4. Shin C, Joo S, Kim J, Kim T. Prevalence and correlates of habitual snoring in high school students. Chest 2003;124:17091715.

5. Cho SJ, Kim EY, Rho YI, Yang ES, Park YB, Moon KR, et al. Prevalence and associated factors of snoring in school-aged children. Korean J Pediatr 2002;45:1340-1345.

6. Narang I, Mathew JL. Childhood obesity and obstructive sleep apnea. J Nutr Metab 2012;2012:134202.

7. Goldstein NA, Aronin C, Kantrowitz B, Hershcopf R, Fishkin $\mathrm{S}$, Lee $\mathrm{H}$, et al. The prevalence of sleep-disordered breathing in children with asthma and its behavioral effects. Pediat Pulmonol 2015;50:1128-1136.

8. Redline S, Tishler PV, Schluchter M, Aylor J, Clark K, Graham G. Risk factors for sleep-disordered breathing in children. Associations with obesity, race, and respiratory problems. Am J Respir Crit Care Med 1999;159:1527-1532.

9. Sun K, Zhang Y, Tian Y, Jiang X. Environmental tobacco smoke exposure and risk of habitual snoring in children: a meta-analysis. J Epidemiol Community Health 2018;72: 1064-1070.

10. Verhulst SL, Van Gaal L, De Backer W, Desager K. The prevalence, anatomical correlates and treatment of sleep-disordered breathing in obese children and adolescents. Sleep
Med Rev 2008:12:339-346

11. Montgomery-Downs HE, Crabtree VM, Sans Capdevila O, Gozal D. Infant-feeding methods and childhood sleep-disordered breathing. Pediatrics 2007;120:1030-1035.

12. Brew BK, Marks GB, Almqvist C, Cistulli PA, Webb K, Marshall NS. Breastfeeding and snoring: a birth cohort study. PLoS One 2014;9:e84956.

13. da Silva Gusmão Cardoso T, Pompéia S, Miranda MC. Cognitive and behavioral effects of obstructive sleep apnea syndrome in children: a systematic literature review. Sleep Med 2018:46:46-55.

14. Sedky K, Bennett DS, Carvalho KS. Attention deficit hyperactivity disorder and sleep disordered breathing in pediatric populations: a meta-analysis. Sleep Med Rev 2014;18:349356.

15. Amiri S, AbdollahiFakhim S, Lotfi A, Bayazian G, Sohrabpour $\mathrm{M}$, Hemmatjoo T. Effect of adenotonsillectomy on ADHD symptoms of children with adenotonsillar hypertrophy and sleep disordered breathing. Int I Pediatr Otorhinolaryngol 2015;79:1213-1217.

16. Smith DL, Gozal D, Hunter SJ, Kheirandish-Gozal L. Frequency of snoring, rather than apnea-hypopnea index, predicts both cognitive and behavioral problems in young children. Sleep Med 2017:34:170-178.

17. Chervin RD, Hedger K, Dillon JE, Pituch KJ. Pediatric sleep questionnaire (PSQ): validity and reliability of scales for sleep-disordered breathing, snoring, sleepiness, and behavioral problems. Sleep Med 2000;1:21-32.

18. Chervin RD, Weatherly RA, Garetz SL, Ruzicka DL, Giordani BJ, Hodges EK, et al. Pediatric sleep questionnaire: prediction of sleep apnea and outcomes. Arch Otolaryngol Head Neck Surg 2007;133:216-222.

19. DuPaul GJ, Power TJ, McGoey KE, Ikeda MJ, Anastopoulos AD. Reliability and validity of parent and teacher ratings of attention-deficit/hyperactivity disorder symptoms. J Psychoeduc Assess 1998; 16:55-68.

20. Döpfner M, Steinhausen HC, Coghill D, Dalsgaard S, Poole L, Ralston SJ, et al.; ADORE Study Group. Cross-cultural reliability and validity of $A D H D$ assessed by the $A D H D$ rating scale in a pan-European study. Eur Child Adolesc Psychiatry 2006;15 Suppl 1:i46-i55.

21. So YK, Noh JS, Kim YS, Ko SG, Koh YJ. The reliability and validity of Korean parent and teacher $A D H D$ rating scale. Korean Neuropsychiatr Assoc 2002;41:283-289.

22. Cho SC, Hong YC, Kim JW, Park S, Park MH, Hur J, et al Association between urine cotinine levels, continuous performance test variables, and attention deficit hyperactivity disorder and learning disability symptoms in school-aged children. Psychol Med 2013;43:209-219.

23. Yang SJ, Cheong SS, Hong SD. Prevalence and correlates of attention deficit hyperactivity disorder: school-based mental health services in Seoul. J Korean Neuropsychiatr Assoc 2006:45:69-76 
24. Moon JS, Lee SY, Nam CM, Choi JM, Choe BK, Seo JW, et al. 2007 Korean National Growth Charts: review of developmental process and an outlook. Korean J Pediatr 2008;51: 1-25.

25. Kara CO, Ergin H, Koçak G, Kiliç I, Yurdakul M. Prevalence of tonsillar hypertrophy and associated oropharyngeal symptoms in primary school children in Denizli, Turkey. Int J Pediatr Otorhinolaryngol 2002;66:175-179.

26. Ersu R, Arman AR, Save D, Karadag B, Karakoc F, Berkem M, et al. Prevalence of snoring and symptoms of sleep-disordered breathing in primary school children in istanbul. Chest 2004; 126:19-24.

27. Corbo GM, Fuciarelli F, Foresi A, De Benedetto F. Snoring in children: association with respiratory symptoms and passive smoking. BMJ 1989;299:1491-1494.

28. Spruyt K, O'Brien LM, Macmillan Coxon AP, Cluydts R, Verleye $\mathrm{G}$, Ferri R. Multidimensional scaling of pediatric sleep breathing problems and bio-behavioral correlates. Sleep Med 2006; 7:269-280.

29. Anuntaseree W, Rookkapan K, Kuasirikul S, Thongsuksai P. Snoring and obstructive sleep apnea in Thai school-age children: prevalence and predisposing factors. Pediatr Pulmonol 2001;32:222-227.

30. Ng DK, Kwok KL, Cheung JM, Leung SY, Chow PY, Wong $\mathrm{WH}$, et al. Prevalence of sleep problems in Hong Kong primary school children: a community-based telephone survey. Chest 2005;128:1315-1323.

31. Bonuck KA, Chervin RD, Cole TJ, Emond A, Henderson J, Xu $\mathrm{L}$, et al. Prevalence and persistence of sleep disordered breathing symptoms in young children: a 6-year populationbased cohort study. Sleep 2011;34:875-884.

32. Papaioannou G, Kambas I, Tsaoussoglou M, PanaghiotopoulouGartagani P, Chrousos G, Kaditis AG. Age-dependent changes in the size of adenotonsillar tissue in childhood: implications for sleep-disordered breathing. J Pediatr 2013;162:269-274.e4.

33. Kang KT, Chou CH, Weng WC, Lee PL, Hsu WC. Associations between adenotonsillar hypertrophy, age, and obesity in children with obstructive sleep apnea. PLoS One 2013;8:e78666.

34. Verhulst S. Sleep-disordered breathing and sleep duration in childhood obesity. In: Freemark M, editor. Pediatric obesity: etiology, pathogenesis, and treatment. New York:Humana Press;2010. p.241-252.

35. Urschitz MS, Guenther A, Eitner S, Urschitz-Duprat PM, Schlaud M, Ipsiroglu OS, et al. Risk factors and natural history of habitual snoring. Chest 2004;126:790-800.

36. Chay OM, Goh A, Abisheganaden J, Tang J, Lim WH, Chan $\mathrm{YH}$, et al. Obstructive sleep apnea syndrome in obese Singapore children. Pediatr Pulmonol 2000;29:284-290.
37. Kaditis AG, Finder J, Alexopoulos El, Starantzis K, Tanou K, Gampeta S, et al. Sleep-disordered breathing in 3,680 Greek children. Pediatr Pulmonol 2004;37:499-509.

38. Li AM, Au CT, So HK, Lau J, Ng PC, Wing YK. Prevalence and risk factors of habitual snoring in primary school children. Chest 2010;138:519-527.

39. Youssef NA, Ege M, Angly SS, Strauss JL, Marx CE. Is obstructive sleep apnea associated with ADHD? Ann Clin Psychiatry 2011;23:213-224.

40. Chervin RD, Ruzicka DL, Giordani BJ, Weatherly RA, Dillon JE, Hodges EK, et al. Sleep-disordered breathing, behavior, and cognition in children before and after adenotonsillectomy. Pediatrics 2006; 117:e769-e778.

41. Marcus CL, Moore RH, Rosen CL, Giordani B, Garetz SL, Taylor HG, et al.; Childhood Adenotonsillectomy Trial (CHAT). A randomized trial of adenotonsillectomy for childhood sleep apnea. N Engl J Med 2013;368:2366-2376.

42. Biggs SN, Vlahandonis A, Anderson V, Bourke R, Nixon GM, Davey MJ, et al. Long-term changes in neurocognition and behavior following treatment of sleep disordered breathing in school-aged children. Sleep 2014;37:77-84.

43. Weichard AJ, Walter LM, Hollis SL, Nixon GM, Davey MJ, Horne RSC, et al. Association between slow-wave activity, cognition and behaviour in children with sleep-disordered breathing. Sleep Med 2016;25:49-55.

44. Mulvaney SA, Goodwin JL, Morgan WJ, Rosen GR, Quan SF, Kaemingk KL. Behavior problems associated with sleep disordered breathing in school-aged children--the Tucson children's assessment of sleep apnea study. J Pediatr Psychol 2006;31:322-330.

45. Yazici KU, Yazici IP, Ustundag B. Increased serum hepcidin levels in childrenand adolescents with attention deficit hyperactivity disorder. Clin Psychopharmacol Neurosci 2019;17: 105-112.

46. Subcommittee on Attention-Deficit/Hyperactivity Disorder; Steering Committee on Quality Improvement and Management, Wolraich M, Brown L, Brown RT, DuPaul G, Earls M, Feldman HM, et al. ADHD: clinical practice guideline for the diagnosis, evaluation, and treatment of attention-deficit/hyperactivity disorder in children and adolescents. Pediatrics 2011; 128:1007-1022.

47. Akinbami LJ, Ogden CL. Childhood overweight prevalence in the United States: the impact of parent-reported height and weight. Obesity (Silver Spring) 2009;17:1574-1580.

48. Cantwell DP, Lewinsohn PM, Rohde P, Seeley JR. Correspondence between adolescent report and parent report of psychiatric diagnostic data. J Am Acad Child Adolesc Psychiatry 1997;36:610-619. 